\title{
Malaria and HIV coinfection in sub-Saharan Africa: prevalence, impact, and treatment strategies
}

This article was published in the following Dove Press journal:

Research and Reports in Tropical Medicine

\author{
Tebit E Kwenti ${ }^{1,2}$ \\ 'Department of Medical Laboratory \\ Sciences, Faculty of Health Sciences, \\ University of Buea, ${ }^{2}$ Regional Hospital \\ Buea, Buea, Cameroon
}

\begin{abstract}
Malaria and HIV, two of the world's most deadly diseases, are widespread, but their distribution overlaps greatly in sub-Saharan Africa. Consequently, malaria and HIV coinfection (MHC) is common in the region. In this paper, pertinent publications on the prevalence, impact, and treatment strategies of MHC obtained by searching major electronic databases (PubMed, PubMed Central, Google Scholar, ScienceDirect, and Scopus) were reviewed, and it was found that the prevalence of MHC in SSA was $0.7 \%-47.5 \%$ overall. Prevalence was $0.7 \%-47.5 \%$ in nonpregnant adults, $1.2 \%-27.8 \%$ in children, and $0.94 \%-37 \%$ in pregnant women. MHC was associated with an increased frequency of clinical parasitemia and severe malaria, increased parasite and viral load, and impaired immunity to malaria in nonpregnant adults, children, and pregnant women, increased in placental malaria and related outcomes in pregnant women, and impaired antimalarial drug efficacy in nonpregnant adults and pregnant women. Although a few cases of adverse events have been reported in coinfected patients receiving antimalarial and antiretroviral drugs concurrently, available data are very limited and have not prompted major revision in treatment guidelines for both diseases. Artemisinin-based combination therapy and cotrimoxazole are currently the recommended drugs for treatment and prevention of malaria in HIV-infected children and adults. However, concurrent administration of cotrimoxazole and sulfadoxine-pyrimethamine in HIV-infected pregnant women is not recommended, because of high risk of sulfonamide toxicity. Further research is needed to enhance our understanding of the impact of malaria on HIV, drug-drug interactions in patients receiving antimalarials and antiretroviral drugs concomitantly, and the development of newer, safer, and more cost-effective drugs and vaccines to prevent malaria in HIV-infected pregnant women.
\end{abstract}

Keywords: malaria, HIV, coinfection, prevalence, treatment, sub-Saharan Africa

\section{Introduction}

Malaria and HIV, two of the most deadly diseases of our time, ${ }^{1,2}$ are still a major public health menace in sub-Saharan Africa (SSA). Both diseases are widespread, but their distribution greatly overlaps in SSA. Consequently, malaria and HIV coinfection (MHC) is common in the region. Malaria, a protozoan parasitic disease, accounted for 216 million cases and 445,000 deaths in 2016, approximately $90 \%$ of cases and deaths occurring in SSA, ${ }^{3}$ while HIV, a viral disease, accounted for 36.7 million cases and about 1 million deaths in 2016. ${ }^{4}$ SSA also has the lion's share of the global HIV burden (approximately 70\%). ${ }^{5}$ Both diseases affect the poorest segment of a population, made vulnerable by the lack of access to quality education, information, and state services, all characteristic of SSA. In effect, malaria and HIV could be said to be exacerbated and reinforced by poverty by affecting young people who would have otherwise enter
Tespondence: Tebit E Kwent Department of Medical Laboratory Sciences, Faculty of Health Sciences, University of Buea, PB 63, Buea, Southwest Region, Cameroon Tel +237697979776 Email kwentitebit@yahoo.com
Research and Reports in Tropical Medicine 2018:9 I23-I36 (cc) (i) (5) 02018 Kwenti. This work is published and licensed by Dove Medical Press Limited. The full terms of this license are available at https://www.dovepress.com/terms. BY NC php and incorporate the Creative Commons Attribution - Non Commercial (unported, v3.0) License (http://(creativecommons.org/licenses/by-nc/3.0/). By accessing the work you hereby accept the Terms. Non-commercial uses of the work are permitted without any further permission from Dove Medical Press Limited, provided the work is properly attributed. For permission for commercial use of this work, please see paragraphs 4.2 and 5 of our Terms (https://www.dovepress.com/terms.php). 
the workforce and contribute to the local economy. The coendemicity of malaria and HIV in SSA has generated so much interest in the study of both diseases recently, because of possible drug-drug interactions in MHC patients receiving malaria and HIV treatment concomitantly, as well as their impact on the control of either disease. ${ }^{6-8}$

Together, malaria and HIV account for over 2 million deaths globally every year. ${ }^{9,10}$ Children (especially those $<5$ years of age) and pregnant women are at greatest risk of malaria morbidity and death, ${ }^{11,12}$ and women and adolescent girls are the most vulnerable to HIV infection. ${ }^{4}$ Pregnant women and their unborn babies are at particular risk of MHC: approximately 1 million pregnancies are complicated by MHC every year in SSA, ${ }^{13}$ putting the life of the pregnant woman and her infant at risk. Adverse pregnancy outcomes associated with MHC include low birth weight, preterm delivery, higher rates of neonatal mortality, placental malaria infection, severe anemia, slow gestational development, reduced transfer of maternal antibodies (that confer protection against other infectious diseases) from mother to child, and in some cases increased risk of mother-child transmission of HIV. ${ }^{14,15}$

Studies had failed to demonstrate any meaningful interaction between malaria and HIV, but a recent study showed one that was synergistic and bidirectional, ${ }^{16}$ leading to an exponential increase in the adverse events caused by either infection. Studies suggest the effect of MHC is greater in patients with advanced and suppressed immune function. Malaria and HIV interact in different ways: 1) biologically, malaria in HIV-infected patients leads to an increase in viremia and a decline in $\mathrm{CD}^{+} \mathrm{T}$-cell count, potentially worsening the clinical outlook of HIV-infected persons and promoting HIV transmission, ${ }^{17,18}$ and MHC persons are more likely to harbor parasites at a high density; ${ }^{19}$ 2) clinically, HIV contributes to more frequent and more severe malaria, commonly anemia and cerebral malaria, ${ }^{20}$ and increased risk of congenital infection, while malaria increases the disease progression of HIV to AIDS; 3) immunologically, malaria and HIV interact with the host's immune system, leading to complex activation of immune cells and subsequent tightly regulated production of cytokines and antibodies; and 4) therapeutically, HIV infection can impair the efficacy of antimalarial treatment, increase adverse events, and select for parasites with drug-resistant mutations. ${ }^{19,21}$

There is sufficient evidence to show that MHC exponentially increases the adverse effects of one infection on the other, has a negative impact on the prognosis, and complicates the prevention and treatment of both infections in SSA. A clear understanding of both diseases and their interaction is necessary for effective control, particularly in SSA, where the burden is highest. This paper reviews the pertinent publications on the prevalence of $\mathrm{MHC}$, the impact of $\mathrm{MHC}$ in terms of biological, clinical, immunological, and therapeutic outcomes (not leaving out the impact on the transmission of one on the other), and treatment strategies for malaria and HIV in MHC patients, and concludes with some future perspectives.

\section{Methods}

Multiple electronic databases - PubMed, PubMed Central, Google Scholar, ScienceDirect, and Scopus - were searched using the keywords "malaria", "HIV", "co-infection", "prevalence", "interaction", "treatment", and "SSA". Reference sections in articles were also reviewed to find other relevant studies. Articles reporting the prevalence of $\mathrm{MHC}$, interaction between malaria and HIV, treatment of malaria in HIV-coinfected patients and vice versa in SSA published up to 2018 were included for data extraction.

\section{Prevalence of malaria and HIV coinfection (MHC) in SSA}

Geographically, malaria and HIV are concentrated in tropical and subtropical regions of the world, including SSA. Approximately $70 \%$ of the world's HIV-infected population lives in SSA, where 350 million people are exposed to infection with malaria. ${ }^{22,23}$ Because of this overlapping distribution, MHC is to be expected. A systematic review of HIV1 infection in Africa revealed malaria to be the third-highest cause of HIV-related morbidity. ${ }^{24}$ Studies conducted in this region have demonstrated heterogeneity in the distribution of MHC. Reported prevalence varies considerably across different populations and geographical settings in SSA. A majority of studies published thus far have reported MHC prevalence in adults (including nonpregnant women), while few have been conducted on children and pregnant women, thereby leaving a void in our understanding of the epidemiology of MHC in these groups (Table 1). Generally, MHC prevalence is $0.7 \%-72 \%$ in SSA: $0.7 \%-47.5 \%$ in nonpregnant adults, $1.2 \%-27.8 \%$ in children, and $0.94 \%-37 \%$ in pregnant women. A meta-analysis performed in 2016 revealed overall pooled prevalence of MHC in SSA was $19 \%, 26 \%$ in adults, $12 \%$ in pregnant women, and $9 \%$ in children. ${ }^{25}$ Most studies (but not all $)^{26}$ conducted so far have failed to observe any significant association between MHC and sex or age.

Studies that have been conducted in SSA rarely report the infecting Plasmodium spp. in MHC (Table 1). Just a 
Table I Summary of studies reporting the prevalence of malaria and HIV coinfection in SSA

\begin{tabular}{|c|c|c|c|c|c|}
\hline Site & $\begin{array}{l}\text { MHC } \\
\text { prevalence }\end{array}$ & $\begin{array}{l}\text { Plasmodium } \\
\text { spp. } \\
\text { reported }\end{array}$ & Design & Other significant findings & Reference \\
\hline \multicolumn{6}{|c|}{ Adults and nonpregnant women } \\
\hline Lagos, Nigeria & $47.5 \%$ & $\begin{array}{l}\text { P. falciparum, } \\
\text { P. malariae }\end{array}$ & Cross-sectional & $\begin{array}{l}\text { Prevalence of malaria higher in HIV-infected vs uninfected } \\
\text { subjects ( } P=0047) \\
\text { Anemia prevalence higher in coinfected }(258 \%) \text { vs HIV } \\
\text { monoinfected ( } 111 \%) \text { patients }\end{array}$ & 27 \\
\hline $\begin{array}{l}\text { Bobo-Dioulasso, } \\
\text { Burkina Faso }\end{array}$ & $3.09 \%$ & NR & $\begin{array}{l}\text { Prospective }+ \\
\text { retrospective }\end{array}$ & Anemia prevalence higher in coinfected patients & 20 \\
\hline Kano, Nigeria & $27.7 \%$ & $\begin{array}{l}\text { P. falciparum } \\
(99.1 \%)\end{array}$ & & $\begin{array}{l}\text { Prevalence of coinfection higher in HIV patients not on ART } \\
\text { Prevalence of coinfection lower among patients on Ctx } \\
\text { prophylaxis } \\
\text { CD4 } 4^{+} \text {-cell count lower in coinfected compared to HIV } \\
\text { monoinfected patients }(P=0.035) \\
\text { Prevalence lower among regular ITN users ( } 225 \% \text { vs } 429 \%)\end{array}$ & 28 \\
\hline Kinshasa, Congo & $20.33 \%$ & NR & Cross-sectional & & 31 \\
\hline Kpando, Ghana & $41 \%$ & NR & Cross-sectional & & 31 \\
\hline Nigeria & $32.2 \%$ & NR & Cross-sectional & $\begin{array}{l}\text { Female sex, immunosuppression }\left(\mathrm{CD} 4^{+} \mathrm{T} \text { cells }<350\right) \text { and not } \\
\text { using ITNs predicted occurrence of clinical malaria in HIV- } \\
\text { infected patients }\end{array}$ & 26 \\
\hline Mozambique & $33.02 \%$ & NR & Cross-sectional & $\begin{array}{l}\text { In-hospital mortality higher in coinfected patients compared to } \\
\text { controls (I30\% vs I7\%) } \\
\text { More frequent respiratory distress, bleeding disorders, } \\
\text { hypoglycemia, and liver and renal failure in coinfected patients }\end{array}$ & 32 \\
\hline Rwanda $^{\mathrm{a}}$ & $12.96 \%$ & NR & & & \\
\hline Ghana & $4.4 \%$ & NR & Retrospective & & 33 \\
\hline $\begin{array}{l}\text { Beira, } \\
\text { Mozambique }\end{array}$ & $28.2 \%$ & NR & Cross-sectional & $\begin{array}{l}\text { Prevalence of severe malaria higher among HIV-infected } \\
\text { compared to HIV-negative subjects }(6 I 7 \% \text { vs } 472 \%) \\
\text { Lower } \mathrm{Hb} \text { among coinfected vs HIV monoinfected subjects } \\
(P=0003) \\
\text { Lower prevalence of malaria in HIV-infected persons receiving } \\
\text { Ctx prophylaxis }\end{array}$ & 34 \\
\hline Ghana & $11.75 \%$ & NR & Cross-sectional & $\begin{array}{l}\text { Anemia prevalence higher among coinfected patients } \\
\text { CD4 } 4^{+} \mathrm{T} \text {-cell counts lower among coinfected patients }\end{array}$ & 35 \\
\hline Oromia, Ethiopia & $0.7 \%$ & NR & Cross-sectional & $\begin{array}{l}\text { Lower prevalence among HIV-infected patients who visit health } \\
\text { facility for routine follow-up } \\
\text { Prevalence of malaria lower in HIV-infected patients receiving } \\
\text { Ctx prophylaxis }\end{array}$ & 36 \\
\hline $\begin{array}{l}\text { Yaoundé, } \\
\text { Cameroon }\end{array}$ & $7.3 \%$ & NR & Cross-sectional & $\begin{array}{l}\text { Prevalence of malaria higher in HIV-infected patients, those with } \\
\text { lower CD4 } 4^{+} \mathrm{T} \text {-cell counts, and those not sleeping under ITNs } \\
\text { Prevalence of coinfection lower in coinfected patients on Ctx } \\
\text { prophylaxis }\end{array}$ & 5 \\
\hline Nigeria & $18.5 \%$ & NR & Cross-sectional & Mean $\mathrm{Hb}$ and PCV lower among coinfected patients & 37 \\
\hline Ethiopia & $17.4 \%$ & NR & Cross-sectional & $\begin{array}{l}\text { Higher prevalence of coinfection among rural residents } \\
\text { Prevalence of anemia higher among coinfected patients } \\
\text { compared to HIV-negative subjects }\end{array}$ & 38 \\
\hline Abuja, Nigeria & $29.2 \%$ & NR & Cross-sectional & $\begin{array}{l}\text { Malaria-parasite density higher in coinfected patients with lower } \\
\text { CD4 }{ }^{+} \text {T-cell count (negative correlation) }\end{array}$ & 30 \\
\hline Abakaliki, Nigeria & $19.4 \%$ & $\begin{array}{l}\text { P. falciparum } \\
(72.6 \%) \text {, } \\
\text { P. vivax }(27.4 \%)\end{array}$ & Retrospective & $\begin{array}{l}\text { Mean } \mathrm{CD} 4^{+} \mathrm{T} \text {-cell count and } \mathrm{Hb} \text { lower in coinfected vs HIV } \\
\text { monoinfected patients }\end{array}$ & 29 \\
\hline Mozambique & $72 \%$ & $N R$ & Cross-sectional & & 39 \\
\hline Pregnant wome & & & & & \\
\hline Ethiopia $^{\mathrm{a}}$ & $0.94 \%$ & NR & Cross-sectional & & 40 \\
\hline Ibadan, Nigeria & $22.8 \%$ & NR & Cross-sectional & & 41 \\
\hline $\begin{array}{l}\text { Douala, } \\
\text { Cameroon }\end{array}$ & $17.3 \%$ & NR & Cross-sectional & $\begin{array}{l}\text { Lower mean } \mathrm{Hb} \text { among coinfected compared to HIV- } \\
\text { monoinfected women }\end{array}$ & 42 \\
\hline
\end{tabular}


Table I (Continued)

\begin{tabular}{|c|c|c|c|c|c|}
\hline Site & $\begin{array}{l}\text { MHC } \\
\text { prevalence }\end{array}$ & $\begin{array}{l}\text { Plasmodium } \\
\text { spp. } \\
\text { reported }\end{array}$ & Design & Other significant findings & Reference \\
\hline Ghana & $20.3 \%$ & NR & Cross-sectional & $\begin{array}{l}\text { Prevalence higher among HIV-infected patients compared to } \\
\text { HIV-negative patients }\end{array}$ & 43 \\
\hline Nigeria & $37.5 \%$ & NR & Cross-sectional & $\begin{array}{l}\text { Higher prevalence in HIV-infected women } \\
\text { Low birth weight in coinfected women }\end{array}$ & 44 \\
\hline Rwanda & $13.3 \%$ & NR & Cross-sectional & $\mathrm{CD}^{+} \mathrm{T}$ cells $<350$ associated with higher risk of coinfection & 45 \\
\hline Nigeria & $18.5 \%$ & NR & & & 37 \\
\hline \multicolumn{6}{|l|}{ Children } \\
\hline Ibadan, Nigeria & $27.8 \%$ & NR & Cross-sectional & & 41 \\
\hline Kenya & $12 \%$ & NR & Cross-sectional & $\begin{array}{l}\text { Malaria-parasite density higher in coinfected patients compared } \\
\text { to malaria-monoinfected patients }\end{array}$ & 46 \\
\hline Mozambique & $11 \%$ & NR & Cross-sectional & $\begin{array}{l}\text { Higher prevalence of severe malaria (severe acidosis, anemia, and } \\
\text { respiratory distress and higher peripheral blood parasitemia) and } \\
\text { mortality in HIV-infected children ( } 26 \% \text { vs } 9 \%)\end{array}$ & 39 \\
\hline $\begin{array}{l}\text { Yaoundé, } \\
\text { Cameroon }\end{array}$ & $1.2 \%$ & NR & Cross-sectional & & 47 \\
\hline Malawi & $15 \%$ & NR & & & 48 \\
\hline Sokoto, Nigeria & $31 \%$ & NR & Cross-sectional & Prevalence of coinfection higher in males & 49 \\
\hline $\begin{array}{l}\text { Abidjan, Côte } \\
\text { d'lvoire }\end{array}$ & $18.3^{\mathrm{a}}$ & NR & Cohort study & $\begin{array}{l}\text { Higher incidence of malaria in HIV-infected children not } \\
\text { receiving Ctx prophylaxis }\end{array}$ & 50 \\
\hline
\end{tabular}

Note: ancidence of malaria per 100 children.

Abbreviations: NR, not reported; Ctx, cotrimoxazole; Hb, hemoglobin; MHC, malaria and HIV coinfection; SSA, sub-Saharan Africa; ITN, insecticide-treated net; ART, antitretroviral therapy; PCV, pack cell volume.

handful of studies have reported these. ${ }^{27-30}$ It is well known that Plasmodium falciparum, which happens to be the most virulent of the plasmodia, is the principal species in circulation in $\mathrm{SSA},{ }^{3}$ but today molecular evidence shows that other Plasmodium spp. are increasingly causing malaria in the region. For example, Wondinmeneh et $\mathrm{al}^{29}$ reported a prevalence of $P$. vivax of $27.4 \%$ among $\mathrm{MHC}$ patients in Nigeria. A growing number of epidemiological studies are also reporting species other than $P$. falciparum causing malaria in the general population in SSA. These other species of plasmodia ( $P$. vivax, $P$. malariae, and $P$. ovale) may be interacting with HIV differently than previously thought, necessitating further research to provide a clearer picture of malaria and HIV interaction in SSA.

\section{Impact of MHC in SSA}

Separately, malaria and HIV have a profound physiological impact on infected patients. ${ }^{51}$ In immunocompetent patients, malaria infection produces a spectrum of clinical manifestations of severe anemia, respiratory distress, cerebral malaria, coma, multiorgan failure, or death. ${ }^{12}$ Anemia is a common manifestation in SSA, especially in children and pregnant women, and malaria is one of its major causes. ${ }^{52} \mathrm{HIV}$, on the other hand, infects and depletes $\mathrm{CD}^{+} \mathrm{T}$ cells, thereby exposing infected patients to opportunistic infections. HIV is also associated with dysregulation of proinflammatory cytokines and chemokines in plasma and lymph nodes, thereby influencing disease progression. ${ }^{53}$ Proinflammatory cytokines are known to play an important role in both the control and pathogenesis of both diseases, and are the potential means by which HIV affects the disease course and outcome in other infections, such as malaria. ${ }^{51}$ Table 2 presents a summary of the impact of HIV on malaria and vice versa.

\section{Impact on transmission}

In coendemic areas, malaria and HIV each have an impact on the transmission of the other. Malaria leads to an increase in the viral load of HIV and hence increases the probability of transmission of HIV, thereby increasing HIV prevalence. ${ }^{18}$ This may explain why SSA also has the highest burden of HIV. It has been postulated that without the amplification effect caused by malaria, HIV decreases to extinction. ${ }^{16}$ Repeated transient increases in HIV load resulting from coinfection with malaria have been proposed as an important factor in the rapid spread of HIV infection in SSA. ${ }^{17}$ Using a mathematical model, scientists were able to estimate that an increase in viral load was associated with a 2.45 -fold increase in transmission probability of HIV. ${ }^{54}$ However, the effect of malaria on HIV load may not be significant in HIV-infected children compared to adults, as children generally have higher baseline viral loads than adults. Therefore, the relative influence of malaria on HIV load may not be as great. ${ }^{55}$ 
Table 2 Summary of the impact of malaria and HIV coinfection

\begin{tabular}{|c|c|c|c|}
\hline & Nonpregnant adults & Children & Pregnant women \\
\hline \multicolumn{4}{|l|}{ HIV impact on malaria } \\
\hline Increased incidence of clinical malaria & $+^{5,27,34,38}$ & $+^{15,46,50,83}$ & $++^{15,27,43,44,51,51}$ \\
\hline Increased in malaria-associated mortality & $++^{32,73}$ & $++^{39,48,55,74,79,80,84,85,86,87}$ & $+^{74}$ \\
\hline Increased severity of malaria including anemia & $++^{20,27,29,32,34,35,37,38}$ & $++^{20,39,43}$ & $++^{14,15,42,67-69,77}$ \\
\hline Increased risk of placental malaria & NA & NA & $++^{14,15,27,44,58,78}$ \\
\hline Increased parasite density & $++^{19,30}$ & $?$ & $++^{14,15,51}$ \\
\hline Decreased immunity to malaria & $++^{90,91,96}$ & $?$ & $++^{93-95}$ \\
\hline $\begin{array}{l}\text { Impaired antimalarial drug efficacy and/or increase } \\
\text { in adverse events }\end{array}$ & $+^{43,100,101}$ & $?$ & $++^{14,15,56,99,105,107,124}$ \\
\hline Selection of resistant strains of parasite & $+{ }^{19,100}$ & $++^{19}$ & $?$ \\
\hline \multicolumn{4}{|l|}{ Malaria impact on HIV } \\
\hline Increased HIV viral load & $+^{51,64,104}$ & $?$ & $++^{18}$ \\
\hline Decreased in CD4 ${ }^{+} \mathrm{T}$-cell count & $++^{5,26,28,29,35,104}$ & $?$ & $++^{41,45}$ \\
\hline Increased progression of HIV to AIDS & $++^{13,14,51,102}$ & $?$ & $++^{13,14,51,69}$ \\
\hline Impaired ARV efficacy & $?$ & $?$ & $?$ \\
\hline
\end{tabular}

Notes: + Supported by five studies or fewer; ++ strongly supported by more than five studies; ?, studies highly inconsistent or not performed.

Abbreviation: NA, not applicable.

On the other hand, HIV infection increases the incidence of falciparum parasitemia and is associated with severe malaria by mechanisms that involve immunosuppression. ${ }^{56}$ In a study involving 41 countries in SSA, HIV infection was thought to have caused an average increase in the prevalence of malaria of $1.3 \%$ and malaria-related mortality of $4.9 \%$. The same study also revealed that an extra 3 million cases of clinical malaria and 65,000 malaria-related deaths could be attributable to HIV infection in Africa every year. ${ }^{57}$

The impact of HIV on malaria is modified by such factors as the endemicity and stability of malaria transmission. ${ }^{8,58}$ In areas with stable malaria transmission, HIV has been reported to increase the risk of malaria infection and clinical malaria in adults, especially those with advanced immunosuppression..$^{32}$ In settings with unstable malaria transmission, HIV-infected adults are at increased risk of complicated and severe malaria deaths, ${ }^{59}$ because natural immunity against malaria is not acquired, resulting in a high proportion of malaria cases. This was evident in a prospective study in South Africa, in which HIV-infected patients were observed to have a fourfold-increased risk of severe malaria. ${ }^{60}$ Malaria, on the other hand, has been shown to be significantly associated with HIV infection in eastern SSA, but not in western SSA, suggesting that it might not play an important role in the spread of HIV in populations where the prevalence of HIV is low. ${ }^{61}$ Further studies are required to confirm this. Furthermore, in coendemic areas, the interaction between the two diseases may be influenced by their geographical distribution (in situations where HIV is more prevalent in urban areas and malaria in rural areas) and age (where HIV is more in adults and malaria in children). ${ }^{57}$

\section{Biological and clinical impact of $\mathrm{MHC}$}

The biological basis of the interaction between malaria and HIV is well established. As mentioned earlier, malaria has been associated with an increase in viral load, both in vivo ${ }^{62}$ and in vitro, ${ }^{63}$ and a fall in $\mathrm{CD}^{+}{ }^{+} \mathrm{T}$-cell count, potentially worsening the prognosis of HIV-infected patients ${ }^{13}$ and threatening antiretroviral (ARV)-treatment effectiveness. A prospective cohort study performed among HIV1-infected adults in Malawi revealed HIV1 RNA concentration almost doubled between HIV monoinfection and MHC.$^{64}$ In the same study, it was estimated that on average, malaria generated a 0.25-log increment on mean HIV RNA concentration. Similar observations have been made among Ugandan children living with HIV/AIDS, in whom malaria was observed to increase transiently the HIV viral load by $0.42 \log$ than that reported in adults. ${ }^{65}$ The transient increase in viral load is estimated to last 5-8 weeks (depending on the rate of parasite clearance), but after coinfected parasites have been cleared from the body, the viral load returns to its original viral set point. ${ }^{64}$ The mechanism by which Plasmodium infection enhances HIV1 replication is not fully understood, and is thought to be mediated by malaria antigens..$^{59}$ One study has shown that the mechanism by which P. falciparum induces HIV replication may involve infected red blood cells, which activate $\mathrm{CD} 4^{+}$ $\mathrm{T}$ cells and stimulate HIV replication in a TNF $\alpha$-dependent manner following malarial antigen processing by monocytes/ macrophages. ${ }^{66}$

HIV-associated immunosuppression contributes to more frequent and more severe malaria, commonly anemia and cerebral malaria, ${ }^{8,20}$ increases the risk of placental malaria in pregnant women regardless of gravidity, ${ }^{67-69}$ and increases the 
risk of congenital infection. ${ }^{27}$ Studies have shown that patients with $\mathrm{MHC}$ are twice as likely to be anemic. ${ }^{27}$ Newborns of women infected with HIV and/or malaria are equally at increased risk of anemia. ${ }^{43}$ A Zambian study revealed HIVinfected patients with uncomplicated malaria had a larger decrease in hemoglobin concentration at day 14 and slower recovery at day 45 compared to HIV-uninfected patients. ${ }^{70}$ HIV-infected persons with malaria are also more likely to suffer from recrudescence compared to controls. ${ }^{71}$ Studies investigating the impact of HIV on malaria-parasite density have been inconsistent in their conclusions; most but not all $^{27,72}$ reported higher parasite density in coinfection before and after treatment. ${ }^{19,20}$ A retrospective study conducted in Senegal revealed that malaria-related mortality was higher in $\mathrm{HIV}$-infected patients than HIV-uninfected patients $(58 \%$ vs $19 \%) .^{73}$

In pregnancy, $\mathrm{MHC}$ is associated with higher frequency of clinical malaria and higher parasite density. ${ }^{15,51}$ Maternal mortality is also higher in women with $\mathrm{MHC}$ compared to those with single infection. ${ }^{74}$ About 1 million pregnancies in SSA are complicated by MHC every year. ${ }^{13}$ A Zimbabwean study revealed that malaria symptoms were about four times as likely to develop in HIV-infected pregnant women than in those without HIV. ${ }^{69}$ Pregnant women with MHC are at increased risk of low birth weight and preterm delivery, higher rates of neonatal mortality, placental malaria infection, severe anemia, slow gestational development, reduced transfer of maternal antibodies (conferring protection against other infections) from mother to child, and in some settings increased risk of mother-child transmission of HIV. ${ }^{14,15}$ The risk to the woman and her newborn exists regardless of the number of times a woman has given birth. ${ }^{75}$ First pregnancies are often the most critical, as women develop pregnancy-specific immunity against placental parasites over successive pregnancies (due to repeated exposure). ${ }^{15,76}$ However, available data suggest that women who are living with HIV have the same low level of immunity to malaria in subsequent pregnancies as they do in their first pregnancy and are twice as susceptible to clinical malaria, which increases the risk of adverse outcomes. ${ }^{14,15,77}$ A cohort study conducted in western Kenya demonstrated that MHC more than doubled the risk of moderate-severe anemia in pregnant women. ${ }^{68}$ Furthermore, most studies have reported increased frequency of placental malaria in HIV-infected women, ${ }^{15,58}$ which increases with parity. A review of eleven studies in Africa revealed that the proportion of cases of placental malaria attributable to HIV coinfection increased with the number of pregnancies: $21.3 \%, 41.2 \%$, and $58.2 \%$ for the first pregnancy, second pregnancy, and more than two pregnancies, respectively. ${ }^{78}$ Infant mortality is also high in children born to MHC mothers, ${ }^{75,79,80}$ but this has not been confirmed in subsequent studies. ${ }^{81,82}$

In children, more frequent episodes of clinical malaria have been observed in those HIV-infected compared to HIVuninfected children, and this increases with the severity of immunosuppression. ${ }^{15,83} \mathrm{MHC}$ children have been observed to present with more severe forms of malaria, such as severe acidosis, anemia, respiratory distress, higher parasite density and plasma $P$. falciparum histidine-rich protein, cerebral malaria, and higher case-fatality rates compared to single infection. ${ }^{39,48,55,84,85}$ Results from a prospective study of children with severe malarial anemia needing blood transfusion indicated a higher risk of death at day 7 (HR 2.86), day 28 (HR 3.70), and month 6 (HR 5.70) after treatment in HIVinfected children compared with HIV-uninfected children. ${ }^{86}$ Moreover, Kenyan study also revealed mortality at 3 months after malaria was higher in HIV-infected children compared to HIV-uninfected children (33\% vs $3 \%){ }^{87}$

\section{Immunological impact of $\mathrm{MHC}$}

Malaria immunity is characterized by an age-related reduction in parasite burden, clinical symptoms, and prevalence of severe malaria in individuals residing in endemic areas. ${ }^{88}$ Malaria is often less severe in older adults than in children because of their immunity, which increases with increasing age ${ }^{89}$ Children are thus at increased risk of severe malaria, since they have not yet acquired natural immunity. Pregnant women, particularly primigravid women, transiently lose some of their acquired immunity too.

Available data show conclusively that malaria and HIV infection interact to bring about dysregulation of the immune system. ${ }^{15,51}$ Independently, HIV and malaria interact with the host immune system to bring about complex activation of immune cells, which causes dysfunctional levels of cytokine and antibody production. ${ }^{51}$ In addition, $\mathrm{CD} 4^{+} \mathrm{T}$ cells play a major role in the development and maintenance of antimalaria immunity, but HIV interferes with this immunity, ${ }^{90}$ the mechanism of which includes widespread lymphoid necrosis throughout the lymph nodes, spleen, and gut mucosae, hyperactivation of $\mathrm{CD}^{+}$and $\mathrm{CD}^{+}$effector cells to secrete cytokines, HIV-induced downregulation of $\mathrm{CD}^{+} \mathrm{T}$ cells, decreases in $\mathrm{CD}^{+} \mathrm{T}$-cell counts, and upregulation of parasitemia, consequently leading to fatal malaria and a rapid progression to AIDS. ${ }^{91}$ In one study, HIV infection was observed to be associated with marked blunting of the inflammatory response in a cohort of cerebral malaria in Malawian children. ${ }^{72}$ In another study using simian HIV- 
P. fragile-coinfected macaque models, Trott et $\mathrm{al}^{92}$ showed that Simian immunodeficiency virus infection promoted elevated IL12 levels, suggesting a shift toward immunoactivation as oppose to immunoregulation, thereby leading to immunodysfunction and exhaustion. This thus translates to increased morbidity in MHC.

In pregnancy, HIV is known to weaken pregnancy-specific malaria immunity, implying pregnant $\mathrm{MHC}$ women are more likely to have symptomatic malaria, severe anemia, and placental malaria. ${ }^{15}$ Jaworowski et $\mathrm{a}^{93}$ showed that HIV1 coinfection decreases antibodies to variant surface antigens (VSAs) implicated in pregnancy-associated malaria (PAM) caused by P. falciparum. In multigravida pregnant women with malaria, impaired serum opsonic activity may contribute to anemia and possibly to decreased immunity to PAM-associated with HIV1. ${ }^{93}$ HIV has also been observed to lower VSA-PAM-specific plasma $\operatorname{IgG}_{1}$ and $\mathrm{IgG}_{3}$ and their opsonizing activity in HIV-infected multigravida women, thereby exposing coinfected multigravida women to placental malaria. ${ }^{94}$ This was corroborated by a later study demonstrating that sera from HIV-infected mothers contained fewer antibodies to VSAs in both placental and pediatric isolates of malaria compared to sera from HIV-uninfected mothers..$^{95}$ This lack of gravidity-specific protection against malaria in pregnant women may account for the high risk of complications associated with malaria.

HIV infection also causes changes that lead to abnormal expansion of atypical memory B cells. This has been corroborated by a study conducted in Rwandan adults that demonstrated the expansion of atypical memory B cells and diminished antibody response to a diverse array of P. falciparum antigens in MHC patients. This may explain the higher risk of malaria in HIV-infected individuals. ${ }^{96}$

The immunoresponse elicited may also determine the outcome of MHC, as demonstrated by several studies. Selected T-helper $\left(\mathrm{T}_{\mathrm{H}}\right)-1$ or $\mathrm{T}_{\mathrm{H}} 17 / \mathrm{T}_{\mathrm{H}} 22$ responses after MHC have been shown to correlate with distinct outcomes of virus infection and malaria. ${ }^{91}$ IL12 has been shown to be strongly associated with anaemia ${ }^{87}$ while lower plasma levels of TNF, IL10, and sICAM1 have been associated with cerebral malaria in HIV-infected Malawian children. ${ }^{72}$ Furthermore, raised IL8 and IP10 levels have been observed to be associated with increased disease severity in MHC. ${ }^{97}$ Lower plasma levels of bicyclo- $\mathrm{PGE}_{2}$ in MHC children have also been observed to be associated with reduced hemoglobin concentration, thereby representing a useful marker and mediator of malaria pathogenesis. ${ }^{98} \mathrm{HIV}$ thus negatively impacts the immunoresponse to malaria, particularly premunition in adolescents and adults, and pregnancy-specific immunity, consequently leading to different patterns of disease in HIV-infected patients relative to HIV-uninfected patients.

\section{Therapeutic impact of $\mathrm{MHC}$}

MHC also has a negative impact on the efficacy of antimalarial and/or ARV drugs in patients concomitantly receiving malaria treatment or preventive therapy for malaria and ARV or prophylactic medicines for HIV infection. ${ }^{99} \mathrm{HIV}$ infection has been observed to impair the protection offered by antimalarial treatment and increases the occurrence of adverse events, as well as the selection of mutant strains associated with antimalarial drug resistance. In malaria-endemic areas where HIV prevalence is also high, interaction with ARV drugs, especially protease inhibitors, could affect the utilization of newly introduced artemisinin-based combination therapy (ACT). Adverse events associated with artesunate/ amodiaquine (AS/AQ), including neutropenia, malaise, and anorexia, have been shown to be higher among patients who were concomitantly receiving ARV therapy (ART) ${ }^{21} \mathrm{~A}$ pharmacokinetic study involving artemether-lumefantrine (AL)- and nevirapine-based ART revealed that nevirapinebased ART decreased artemether and dihydroartemisinin area under the plasma concentration-time curve, but unexpectedly increased lumefantrine exposure. ${ }^{100}$ Similar observations have been made for efavirenz. ${ }^{101}$ These interactions may increase the risk of malaria-treatment failure and development of resistance to AL and nevirapine. Antimalarial treatment failure may be more common in HIV-infected adults with low $\mathrm{CD}^{+}$T-cell counts compared to HIV-uninfected adults..$^{99,102}$ In a randomized control trial that compared sulfadoxine-pyrimethamine (SP) with AL for uncomplicated malaria, patients with $\mathrm{CD}^{+}$T-cell counts $<300$ cells $/ \mu \mathrm{L}$ had an increased risk of recurrent malaria (RR 2.24) and recrudescence (RR 1.67), ${ }^{102}$ but recent studies have failed to confirm this. ${ }^{103,104}$ As pointed out by Flateau et al, ${ }^{15}$ impaired acquired immunity in HIV-infected adults but not in children could be responsible for this, as response to treatment also depends on host immunity. In another study, the efficacy of chloroquine and $\mathrm{SP}$ in reducing placental malaria in pregnant HIV1-infected women was impaired compared to pregnant HIV1-negative women. ${ }^{56} \mathrm{~A}$ preliminary study conducted on pregnant women in Mali revealed that $50 \%$ with acute malaria who were concomitantly on nevirapine and quinine had lower therapeutic level of quinine than that recommended. ${ }^{105}$ The same study also found higher concentrations of the quinine's metabolite, 3-hydroxyquinine, suggesting that nevirapine impaired the activity of quinine. In addition, when given 
concomitantly in pregnancy, SP and daily nevirapine can potentially cause fatal liver and skin toxicity. ${ }^{14}$ Severe cutaneous reactions (including Stevens-Johnson syndrome) and clinical hepatitis have been reported in approximately $2 \%$ and $4 \%$, respectively, of patients taking daily nevirapine. ${ }^{14}$ Furthermore, hepatotoxicity has been observed to occur more frequently in women with higher $\mathrm{CD} 4^{+} \mathrm{T}$-cell count. ${ }^{106,107}$ Other ARV drugs have also been reported to interact with antimalarial drugs, ${ }^{15}$ including zidovudine, in which higher mortality rates have been observed in HIV-infected patients, especially those with anemia at baseline. ${ }^{108,109}$

The impact of drug-drug interaction in MHC could be beneficial (in the case where one of the drugs for either malaria or HIV acts synergistically to inhibit the progression of the other). Several studies have shown that protease inhibitors (PIs) can impede the growth of malaria parasites at concentrations that may be of clinical significance. For example, the PIs ritonavir and lopinavir have been observed to inhibit the preerythrocytic and erythrocytic stages of the malaria parasites in vivo and in vitro. ${ }^{110,111}$ The efficacy of PIs have also been observed to depend on the infecting parasite species. For example, Lek-Uthai et $\mathrm{al}^{110}$ showed that ritonavir was four times as effective at inhibiting $P$. vivax than it was at inhibiting $P$. falciparum. On the other hand, antimalarials have also been observed to inhibit HIV replication in the laboratory. For example, one study revealed that chloroquine is capable of inhibiting HIV replication; ${ }^{112}$ however, the clinical implications of these findings remain largely undefined.

Drug-drug interaction between antimalarials and ART could also be deleterious (in the case where one of the drugs antagonizes another and facilitates the progression of the other disease). For example, pyrimethamine has been observed to enhance HIV1 replication significantly in a mechanism that increases HIV Gag proteins without affecting the promoter or reverse-transcriptase activity. ${ }^{113}$ Another deleterious effect of drug-drug interaction is the selection for resistant strains of the parasite. For example, studies have reported elevated day 7 lumefantrine concentration and persistent parasitemia, with strong selection for the Pfmdri codon $86 \mathrm{~N}$ allele among treated HIV subjects on nevirapine, which is a strong indicator for AL-treatment failure or slow clearance in vivo. ${ }^{19,100}$

\section{Treatment strategy for MHC Treatment of malaria}

ACTs containing a combination of either AL, AS-AQ/mefloquine/SP, or dihydroartemisinin-piperaquine are the recommended treatment for malaria in SSA. Unlike in Southeast
Asia, resistance to ACTs has not been reported in SSA. However, resistance has been reported with other antimalarial drugs, including chloroquine and SP in SSA. In some Asian countries, including India, P. falciparum MHC patients have been shown to respond $100 \%$ to malaria treatment. ${ }^{114}$ Contrarily, in SSA, HIV is thought to affect the efficacy of antimalarial drugs negatively. However, such findings are greatly constrained by small samples and are thus inconclusive. Moreover, this is now known to be due to reinfection with new malaria strains, rather than recrudescence of prior infection. ${ }^{115} \mathrm{AL}$, dihydroartemisinin-piperaquine, and AS/ AQ have all been shown to be $100 \%$ efficacious for treating malaria in HIV-infected patients in SSA, notwithstanding the adverse events observed with $\mathrm{AS} / \mathrm{AQ} .{ }^{21} \mathrm{AL}$ has been shown to be efficacious and well tolerated in children in Uganda. ${ }^{116,117}$ Another study has shown that dihydroartemisinin-piperaquine is superior to AL in preventing recurrent parasitemia. ${ }^{21}$ Although there is a wealth of studies showing the potential interaction between ACT and ART, the current evidence is insufficient to modify the general treatment plan for patients with HIV/AIDS. However, because of adverse events, the World Health Organization (WHO) recommends that treatment in HIV-infected patients on zidovudine or efavirenz should if possible avoid AQ-containing ACT regimens, as this increases the risk of neutropenia and hepatoxicity. ${ }^{99}$

\section{Prevention of malaria in pregnant HIV- infected women}

Pregnant HIV-infected women and their infants are the least protected against malaria, despite being the most vulnerable population. Intermittent preventive treatment in pregnancy (IPTp) with SP, a highly effective and recommended approach for preventing pregnancy-related malaria and its complications, is contraindicated for HIV-infected women receiving ART and cotrimoxazole (Ctx; trimethoprim-sulfamethoxazole) prophylaxis for opportunistic infections, due to the risk of sulfonamide-induced adverse drug reactions. ${ }^{99}$ This has been demonstrated in clinical trials, eg, in one trial of twice-weekly SP for AIDS-related opportunistic infections, $6.3 \%$ (6 of 65 ) of patients required discontinuation because of adverse reactions. ${ }^{118}$ Other studies have also reported fatal reactions to SP. ${ }^{119,120}$

In pregnant women not on Ctx, more than two doses of SP are required to achieve the same benefit as two doses of SP in HIV-negative women. ${ }^{121}$ This has been corroborated in more than one study. One prospective cohort study comparing three IPTp regimens with SP (presumptive treatment of fever, two treatments during pregnancy, or monthly treatment) revealed 
that only monthly treatment achieved the same efficacy on placental malaria in HIV-infected and -uninfected women. ${ }^{122}$ In another, monthly treatment with SP reduced the risk for placental malaria by $64 \%$ and the risk of clinical malaria by $66 \%$ in HIV-infected pregnant women compared to two treatments. However, the clinical benefit of monthly treatment vs two doses on premature delivery, low birth weight, and perinatal mortality still needs to be evaluated. In addition, the efficacy of IPTp with SP in women in their first or second pregnancies has been shown to be conserved even in areas of SP resistance, ${ }^{123}$ and is thus recommended in highly endemic areas of SP resistance in combination with insecticide-treated nets (ITNs). ${ }^{14}$

In the absence of SP, the WHO recommends daily Ctx for pregnant immunocompromised HIV-infected women. ${ }^{14}$ Daily use of Ctx has been shown to be efficacious in reducing the incidence of malaria in children and nonpregnant adults. However, there are constraints that may limit its use in pregnant women, including late diagnosis, delay in initiation, fear of the emergence of resistance, and the intolerance, observed with many HIV-infected patients. ${ }^{14}$ Moore et al reported the risk of adverse reaction to Ctx as 26.3 per 100 person-years, and the risk increases with advancing immunosuppression. ${ }^{124}$ There is thus a need to evaluate alternative antimalarial drugs for use in HIV-infected pregnant women, since IPTp with $\mathrm{SP}$ is contraindicated in pregnant women. ${ }^{99}$ Suitable drugs for IPTp must be safe for both the mother and the fetus, able to be given during regular antenatal care visits, and provide long-lasting protection.

\section{Prevention of malaria in HIV-infected children}

In children, there is no indication that HIV impairs clinical and parasitological responses to treatment in uncomplicated malaria, even in those with low $\mathrm{CD}^{+} \mathrm{T}$-cell counts. ${ }^{103,125-127}$ $\mathrm{Ctx}$ as a prophylaxis is also effective in protecting children against malaria in areas of stable malaria transmission. One study showed that HIV-infected children receiving daily Ctx had an $80 \%$ reduced risk of clinical malaria compared to HIV-uninfected children not receiving Ctx. ${ }^{19}$ However that study observed Ctx to be associated with infection with parasites with a rare mutation, dhfr164L, known to mediate high-level antifolate resistance. ${ }^{19}$ Contrary to this is a study conducted in Uganda that showed that although resistance rates of $P$. falciparum to antifolate drugs are high, Ctx prophylaxis in HIV-infected persons was not associated with a higher prevalence of mutations associated with antifolate resistance. ${ }^{128}$ Many other studies have shown that Ctx lowers the risk of clinical malaria in both adults and children with HIV (Table 1). ${ }^{5,50}$ Moreover, adverse events, including moderate-severe neutropenia, have been reported to be more frequent in $\mathrm{HIV}$-infected children receiving $\mathrm{Ctx}$, ART, and AS/AQ concurrently. ${ }^{127}$ Other studies conducted in Mali and Kenya have also found the efficacy of Ctx to be conserved. ${ }^{129,130} \mathrm{Ctx}$ prophylaxis combined with ITNs has been observed to reduce the prevalence of clinical malaria in HIV-infected children by $97 \%$ compared to $43 \%$ for ITNs alone. ${ }^{115}$ Therefore, these drugs should be provided as widely and durably as possible.

\section{Treatment of HIV}

ARTs in current use are classified as nucleoside reversetranscriptase inhibitors, nonnucleoside reverse-transcriptase inhibitors, and PIs. Although studies have demonstrated that PIs are able to inhibit the malaria parasite in vitro and in animals, this has not been proven in human studies. ${ }^{15,131-133}$ However, PIs have been shown to have synergistic effects with chloroquine and mefloquine on $P$. falciparum and $P$. chabaudi in vitro, ${ }^{132,134,135}$ whereas data on interactions with artemisinin are inconsistent. ${ }^{136,137}$ The potential benefits of PIs in the prevention of malaria was demonstrated in a study conducted on Malawian children (aged 4-62 months) in which children on lopinavir-ritonavir in combination with malaria treatment showed a lower risk of recurrent positive blood smear compared to those on zidovudine, lamivudine, and nevirapine. ${ }^{138}$ Another study also found a $41 \%$ reduction in malaria incidence in children receiving lopinavir-ritonavir. ${ }^{139}$ ART combined with $\mathrm{Ctx}$ has also been reported to reduce the frequency of clinical malaria by $92 \%$ compared to $76 \%$ for Ctx alone. ${ }^{140}$ These findings suggest that ART (especially PIs) are important in the management of malaria in $\mathrm{MHC}$, and are thus recommended.

Access to ART is also a key factor in the management of MHC. As mentioned earlier, malaria tends to increase the HIV load, which in turn increases the probability of vertical transmission, especially in pregnant women. ${ }^{18}$ Increased access to ART may serve as a means of mitigating the harmful effects of malaria in MHC. ${ }^{16}$ However, factors that adversely impact treatment outcomes in SSA, including low adherence, poor-quality drugs, resource scarcity, lack of infrastructure, and inadequate treatment, persist in most of the region. ${ }^{44}$

\section{Conclusion}

Available data show a high prevalence of MHC in SSA, which varies considerably from one geographical setting to another. There is sufficient evidence to show that HIV increases the prevalence and severity of clinical malaria in 
adults and children, increases the risk of placental malaria in pregnancy, and undermines malaria treatment in adults and pregnant women. On the other hand, malaria increases the probability of HIV transmission from pregnant mothers to their children and hastens the progression of HIV to AIDS. Furthermore, in coendemic areas, malaria and HIV exert a negative impact on each other in terms of their biological, clinical, and immunological interaction, as well as potential adverse drug-drug interaction that threaten the efficacy of treatment of MHC patients. The high prevalence of coinfection in SSA thus presents a double blow to the region, which is presently worst hit by the presence of other infectious diseases, including tuberculosis. To overcome the burden of $\mathrm{MHC}$ will require a number of strategies.

Firstly, increase access to Ctx prophylaxis and ART. HIV-infected patients who visit the hospital more often with intervals of less than a month have significantly lower odds of coinfection. ${ }^{141}$ Increasing access to treatment facilities will go a long way to curb the burden of malaria in HIV-infected persons. Secondly, there is an urgent need for improvement in malaria control, especially in pregnant women. Malaria control, which can be achieved chiefly by vector control using ITNs and residual spraying, has also been shown to be an effective strategy to curb HIV prevalence. For example, a recent study in Kenya demonstrated that providing longlasting insecticide-treated bed nets and water filters to HIVpositive adults with $\mathrm{CD}^{+}$T-cell counts $>350$ cells $/ \mathrm{mm}^{3}$ significantly reduced the progression of HIV, deferred time to ART eligibility, and saved US\$26 million. ${ }^{142}$ Control of malaria is thus a practical and cost-saving method that could easily be applied in resource-constrained settings, which characterizes most rural areas in SSA.

Thirdly, empirical studies are needed to unlock the mechanism of interaction between malaria and HIV, particularly at the biological level. Studies that have been conducted so far were seriously skewed toward understanding the effect of HIV on malaria, ignoring the effect of malaria on HIV. Lastly, there is a need to accelerate research in the development and field testing of vaccines against malaria and HIV. Considerable progress has been made in the development of a malaria vaccine, and today we have a malaria vaccine - RTS,S/AS01 (Mosquirix). An HIV vaccine has also been developed (RV144) and a Phase III trial in Thailand showed an efficacy of $31 \% .{ }^{143}$ So far, this is the only promising HIV vaccine, and further research is needed in the development of others. ${ }^{144} \mathrm{~A}$ study using models showed that vaccinating macaques with recombinant Listeria $\Delta$ act A prfA* expressing
simian/HIV (sHIV) was protective against life-threatening sHIV-related malaria after sHIV-P. fragile coinfection. ${ }^{145}$ No study has been conducted to determine the efficacy of these malaria or HIV vaccines in protection against $\mathrm{MHC}$ in humans. Human trials are thus required in SSA.

\section{Disclosure}

The author reports no conflicts of interest in this work.

\section{References}

1. Castillo-Chavez C, Levin SA, Shoemaker CA. Mathematical Approaches to Problems in Resource Management and Epidemiology. Heidelberg: Springer; 1987.

2. Murillo D, Roudenko S, Tameru AM, Tatum S. A mathematical model of HIV and malaria co-infection in sub-Saharan Africa. J AIDS Clin Res. 2012;3(7):1000173.

3. World Health Organization. World Malaria Report 2017. Geneva: WHO; 2017.

4. Joint United Nations Programme on HIV and AIDS. Fact sheet: World AIDS Day 2017. 2017. Available from: http://www.unaids.org/sites/ default/files/media_asset/UNAIDS_FactSheet_en.pdf. Accessed April 2, 2018.

5. Njunda AL, Njumkeng C, Nsagha SD, Assob JC, Kwenti TE. The prevalence of malaria in people living with HIV in Yaounde, Cameroon. BMC Public Health. 2016;16:964.

6. Herrero MD, Rivas P, Rallón NI, Ramírez-Olivencia G, Puente S. HIV and malaria. AIDS Rev. 2007;9(2):88-98.

7. Whitworth J, Hewitt K. Effect of malaria on HIV-1 progression and transmission. Lancet. 2005;365(9455):196-197.

8. Idemyor V. Human immunodeficiency virus (HIV) and malaria interaction in sub-Saharan Africa: the collision of two Titans. HIV Clin Trials. 2007;8(4):246-253.

9. Mukandavire Z, Gumel AB, Garira W, et al. Mathematical analysis of a model for HIV-malaria co-infection. Math Biosci Eng. 2009;6(2):333-362.

10. World Health Organization. Malaria in HIV/AIDS Patients. Geneva: WHO; 2017.

11. World Health Organization. World Malaria Report 2015. Geneva: WHO; 2015.

12. Kwenti TE, Kwenti TD, Latz A, Njunda LA, Nkuo-Akenji T. Epidemiological and clinical profile of paediatric malaria: a cross sectional study performed on febrile children in five epidemiological strata of malaria in Cameroon. BMC Infect Dis. 2017;17:499.

13. González R, Ataíde R, Naniche D, Menéndez C, Mayor A. HIV and malaria interactions: where do we stand? Expert Rev Anti Infect Ther. 2012;10(2):153-165.

14. Brentlinger PE, Behrens CB, Micek MA. Challenges in the concurrent management of malaria and HIV in pregnancy in sub-Saharan Africa. Lancet Infect Dis. 2006;6(2):100-111.

15. Flateau C, le Loup G, Pialoux G. Consequences of HIV infection on malaria and therapeutic implications: a systematic review. Lancet Infect Dis. 2011;11(7):541-556.

16. Nyabadza F, Bekele BT, Rúa MA, Malonza DM, Chiduku N, Kgosimore M. The implications of HIV treatment on the HIV-malaria coinfection dynamics: a modeling perspective. Biomed Res Int. 2015;2015:659651.

17. Abu-Raddad LJ, Patnaik P, Kublin JG. Dual infection with HIV and malaria fuels the spread of both diseases in sub-Saharan Africa. Science. 2006;314(5805):1603-1606.

18. Franke MF, Spiegelman D, Ezeamama A, et al. Malaria parasitemia and CD4 T cell count, viral load, and adverse HIV outcomes among HIV-infected pregnant women in Tanzania. Am J Trop Med Hyg. 2010;82(4):556-562. 
19. Chijioke-Nwauche IN. Use of Artemether-Lumefantrine in the Treatment of Asymptomatic-Malaria Infection in HIV-Positive and HIV-Negative Nigerian Adults [doctoral thesis]. London: University of London; 2014.

20. Ouedraogo SM, Sangaré I, Sourabié Y, et al. HIV-malaria coinfection in the Department of Paediatrics of Centre Hospitalier Universitaire Souro SANOU (CHUSS). Afr J Intern Med. 2015;3(4):139-145.

21. Gasasira AF. Interactions between HIV Infection and Malaria in Children Living in sub-Saharan Africa in the Era of Widening Access to Improved Interventions [doctoral thesis]. Berkeley (CA): University of California; 2010

22. World Health Organization. Consolidated Guidelines on the Use of Antiretroviral Drugs for Treating and Preventing HIV Infection: Recommendations for a Public Health Approach. 2nd ed. Geneva: World Health Organization; 2016.

23. Joint United Nations Programme on HIV and AIDS. Global AIDS update. 2016. Available from: http://www.unaids.org/sites/default/files/ media_asset/global-AIDS-update-2016_en.pdf.Accessed April 2, 2018.

24. Holmes CB, Losina E, Walensky RP, Yazdanpanah Y, Freedberg KA. Review of human immunodeficiency virus type 1-related opportunistic infections in sub-Saharan Africa. Clin Infect Dis. 2003;36(5):652-662.

25. Naing C, Sandhu NK, Wai VN. The effect of malaria and HIV coinfection on anemia. Medicine (Baltimore). 2016;95(14):e3205.

26. Iliyasu Z, Babashani M, Abubakar IS, Salahudeen AA, Aliyu MH. Clinical burden and correlates of HIV and malaria co-infection, in northwest Nigeria. Acta Trop. 2013;128(3):630-635.

27. Sanyaolu AO, Fagbenro-Beyioku AF, Oyibo WA, Badaru OS, Onyeabor OS, Nnaemeka CI. Malaria and HIV co-infection and their effect on haemoglobin levels from three healthcare institutions in Lagos, southwest Nigeria. Afr Health Sci. 2013;13(2):295-300.

28. Jegede FE, Oyeyi TI, Abdulrahman SA, et al. Effect of HIV and malaria parasites co-infection on immune-hematological profiles among patients attending anti-retroviral treatment (ART) clinic in Infectious Disease Hospital Kano, Nigeria. PLoS One. 2017;12(3):e0174233.

29. Wondimeneh Y, Ferede G, Atnafu A, et al. HIV-malaria co-infection and their immunohematological profiles. Eur J Exp Biol. 2013;3(1): 497-502.

30. Mustapha J, Emeribe AU, Nasir IA. Survey of malaria and anti-dengue virus IgG among febrile HIV-infected patients attending a tertiary hospital in Abuja, Nigeria. HIV AIDS (Auckl). 2017;9:145-151.

31. Kamanyu EN, Muhindo HM, Wapa-Kamangu CW, Situakibanza HN. Prevalence of malaria infection among people living with HIV in Kinshasa. Open Access Libr J. 2015;2(2):e1077.

32. Berg A, Patel S, Aukrust P, et al. Increased severity and mortality in adults co-infected with malaria and HIV in Maputo, Mozambique: a prospective cross-sectional study. PLoS One. 2014;9(2):e88257.

33. Adu-Gyasi D, Fanello CI, Baiden F, et al. Prevalence of clinically captured and confirmed malaria among HIV seropositive clinic attendants in five hospitals in Ghana. Malar J. 2013;12:382.

34. Saracino A, Nacarapa EA, Massinga EA, et al. Prevalence and clinical features of HIV and malaria co-infection in hospitalized adults in Beira, Mozambique. Malar J. 2012;11:241.

35. Tay SC, Badu K, Mensah AA, Gbedema SY. The prevalence of malaria among HIV seropositive individuals and the impact of the co-infection on their hemoglobin levels. Ann Clin Microbiol Antimicrob. 2015;14:10.

36. Alemayehu G, Melaku Z, Abreha T, et al. Burden of malaria among adult patients attending general medical outpatient department and HIV care and treatment clinics in Oromia, Ethiopia: a comparative cross-sectional study. Malar J. 2015;14:501.

37. Ojurongbe O, Oyeniran OA, Alli OAT. Prevalence of Plasmodium falciparum parasitaemia and its correlation with haematological parameters among HIV-positive individuals in Nigeria. J Trop Med. 2014;2014:161284

38. Beyene HB, Tadesse M, Disassa H, Beyene MB. Concurrent Plasmodium infection, anemia and their correlates among newly diagnosed people living with HIV/AIDS in northern Ethiopia. Acta Trop. 2017;169:8-13.
39. Hendriksen IC, Ferro J, Montoya P, et al. Diagnosis, clinical presentation, and in-hospital mortality of severe malaria in HIV-coinfected children and adults in Mozambique. Clin Infect Dis. 2012;55(8): 1144-1153.

40. Asmamaw T, Alemu A, Alemu A, Unakal C. Prevalence of malaria and HIV among pregnant women attending antenatal clinics at Felege Hiwot Referral Hospital and Addis Zemen Health Center in northwest of Ethiopia. Int J Life Sci Biotechnol Pharm Res. 2013;2(3): $81-91$.

41. Adeoti OM, Anumudu C, Nwuba R, et al. Prevalence of HIV and malaria parasites co-infection in pregnant mothers and their babies post-delivery. J Biol Agric Healthc. 2012;2(6):59-64.

42. Nkuo-Akenji T, Tevoufouet EE, Nzang F, Fon E, Ebong IN. HIV/ AIDS and malaria in pregnant women from Cameroon. Afr J Health Sci. 2011;18(1-2):105-109.

43. Laar AK, Grant FE, Addo Y, et al. Predictors of fetal anemia and cord blood malaria parasitemia among newborns of HIV-positive mothers. BMC Res Notes. 2013;6:350.

44. Uneke CJ, Duhlinska DD, Ujam TN. Effects of maternal Plasmodium falciparum malaria and HIV infection on birth weight in southeastern Nigeria. Mcgill J Med. 2009;12(2):42-49.

45. Ivan E, Crowther NJ, Mutimura E, Osuwat LO, Janssen S, Grobusch MP. Helminthic infections rates and malaria in HIV-infected pregnant women on anti-retroviral therapy in Rwanda. PLoS Negl Trop Dis. 2013;7(8):e2380.

46. Berkley JA, Bejon P, Mwangi T, et al. HIV infection, malnutrition, and invasive bacterial infection among children with severe malaria. Clin Infect Dis. 2009;49(3):336-343.

47. Kwenti TE, Edo E, Ayuk BS, Kwenti TD. Prevalence of coinfection with malaria and HIV among children in Yaoundé, Cameroon: a crosssectional survey performed in three communities in Yaoundé. Yangtze Med. 2017;1(3):178-188.

48. Hochman SE, Madaline TF, Wassmer SC, et al. Fatal pediatric cerebral malaria is associated with intravascular monocytes and platelets that are increased with HIV coinfection. MBio. 2015;6(5):e01390.

49. Onankpa BO, Jiya NM, Yusuf T. Malaria parasitemia in HIV-infected children attending antiretroviral therapy clinic in a teaching hospital. Sahel Med J. 2017;20(1):30-32.

50. Harouna AM, Amorissani-Folquet M, Eboua FT, et al. Effect of cotrimoxazole prophylaxis on the incidence of malaria in HIV-infected children in 2012, in Abidjan, Côte d'Ivoire: a prospective cohort study. BMC Infect Dis. 2015;15:317.

51. Hochman S, Kim K. The impact of HIV and malaria coinfection: what is known and suggested venues for further study. Interdiscip Perspect Infect Dis. 2009;2009:617954.

52. Kwenti TE, Kwenti TD. Anaemia and its association with month and blood phenotype in blood donors in Fako division, Cameroon. BMC Hematol. 2016;16:29.

53. Appay V, Sauce D. Immune activation and inflammation in HIV-1 infection: causes and consequences. J Pathol. 2008;214(2):231-241.

54. Quinn TC, Wawer MJ, Sewankambo N, et al. Viral load and heterosexual transmission of human immunodeficiency virus type $1 . \mathrm{NEngl}$ J Med. 2000;342(13):921-929.

55. Brouwer KC, Mirel LB, Yang C, et al. Subclinical Plasmodium falciparum infection and HIV-1 viral load. Emerg Infect Dis. 2007;13(2): 351-353.

56. Chirenda J, Murugasampillay S. Malaria and HIV co-infection: available evidence, gaps and possible interventions. Cent Afr J Med. 2003;49(5-6):66-71.

57. Korenromp EL, Williams BG, de Vlas SJ, et al. Malaria attributable to the HIV-1 epidemic, sub-Saharan Africa. Emerg Infect Dis. 2005;11(9):1410-1419

58. Focà E, Odolini S, Brianese N, Carosi G. Malaria and HIV in adults: when the parasite runs into the virus. Mediterr J Hematol Infect Dis. 2012;4(1):e2012032.

59. Cuadros DF, Branscum AJ, Crowley PH. HIV-malaria co-infection: effects of malaria on the prevalence of HIV in east sub-Saharan Africa. Int J Epidemiol. 2011;40(4):931-939. 
60. Cohen C, Karstaedt A, Frean J, et al. Increased prevalence of severe malaria in HIV-infected adults in South Africa. Clin Infect Dis. 2005;41(11):1631-1637.

61. Cuadros DF, Branscum AJ, García-Ramos G. No evidence of association between HIV-1 and malaria in populations with low HIV-1 prevalence. PLoS One. 2011;6(8):e23458.

62. Kamya MR, Gasasira AF, Yeka A, et al. Effect of HIV-1 infection on antimalarial treatment outcomes in Uganda: a population-based study. J Infect Dis. 2006;193(1):9-15.

63. Xiao L, Owen SM, Rudolph DL, Lal RB, Lal AA. Plasmodium falciparum antigen-induced human immunodeficiency virus type 1 replication is mediated through induction of tumor necrosis factor- $\alpha$. J Infect Dis. 1998;177(2):437-445.

64. Kublin JG, Patnaik P, Jere CS, et al. Effect of Plasmodium falciparum malaria on concentration of HIV-1-RNA in the blood of adults in rural Malawi: a prospective cohort study. Lancet. 2005;365(9455):233-240.

65. Kiyingi H, Egwang T, Nannyonga M. Prolonged elevation of viral loads in HIV-1-infected children in a region of intense malaria transmission in northern Uganda. Pan Afr Med J. 2010;7:11.

66. Orlov M, Vaida F, Williamson K, et al. Antigen-presenting phagocytic cells ingest malaria parasites and increase HIV replication in a tumor necrosis factor $\alpha$-dependent manner. $J$ Infect Dis. 2014;210(10):1562-1572.

67. Steketee RW, Chilima B, Chitsulo L, Wirima JJ, Bloland PB. Impairment of a pregnant woman's acquired ability to limit Plasmodium falciparum by infection with human immunodeficiency virus type-1. Am J Trop Med Hyg. 1996;55(1 Suppl):42-49.

68. Ayisi JG, van Eijk AM, ter Kuile FO, et al. The effect of dual infection with HIV and malaria on pregnancy outcome in western Kenya. AIDS. 2003;17(4):585-594.

69. Ruperez M. Malaria and HIV: a double threat for pregnant women in sub-Saharan Africa. 2017. Available from: http://gheg-journal. co.uk/2017/07/malaria-hiv-double-threat-for-pregnant-women. Accessed April 2, 2018.

70. van Geertruyden JP, Mulenga M, Chalwe V, et al. Impact of HIV-1 infection on the hematological recovery after clinical malaria. J Acquir Immune Defic Syndr. 2009;50(2):200-205.

71. Shah SN, Smith EE, Obonyo CO, et al. HIV immunosuppression and antimalarial efficacy: sulfadoxine-pyrimethamine for the treatment of uncomplicated malaria in HIV-infected adults in Siaya, Kenya. $J$ Infect Dis. 2006;194(11):1519-1528.

72. Mbale EW, Moxon CA, Mukaka M, et al. HIV coinfection influences the inflammatory response but not the outcome of cerebral malaria in Malawian children. J Infect. 2016;73(3):189-199.

73. Soumaré M, Seydi M, Diop SA, et al. The place of malaria in an infectious disease department in Dakar, Senegal. Med Trop (Mars). 2008;68(5):485-490.

74. Ticconi C, Mapfumo M, Dorrucci M, et al. Effect of maternal HIV and malaria infection on pregnancy and perinatal outcome in Zimbabwe. J Acquir Immune Defic Syndr. 2003;34(3):289-294.

75. Verhoeff FH, Brabin BJ, Hart CA, Chimsuku L, Kazembe P, Broadhead RL. Increased prevalence of malaria in HIV-infected pregnant women and its implications for malaria control. Trop Med Int Health. 1999;4(1):5-12.

76. Fried M, Nosten F, Brockman A, Brabin BJ, Duffy PE. Maternal antibodies block malaria. Nature. 1998;395(6705):851-852.

77. van Eijk AM, Ayisi JG, ter Kuile FO, et al. HIV increases the risk of malaria in women of all gravidities in Kisumu, Kenya. AIDS. 2003;17(4):595-603.

78. ter Kuile FO, Parise ME, Verhoeff FH, et al. The burden of co-infection with human immunodeficiency virus type 1 and malaria in pregnant women in sub-Saharan Africa. Am JTrop Med Hyg. 2004;71(2):41-54.

79. Bloland PB, Wirima JJ, Steketee RW, Chilima B, Hightower A, Breman JG. Maternal HIV infection and infant mortality in Malawi: evidence for increased mortality due to placental malaria infection. AIDS. 1995;9(7):721-726.
80. Gallagher M, Malhotra I, Mungai PL, et al. The effects of maternal helminth and malaria infections on mother-to-child HIV transmission. AIDS. 2005;19(16):1849-1855.

81. Brahmbhatt H, Sullivan D, Kigozi G, et al. Association of HIV and malaria with mother-to-child transmission, birth outcomes, and child mortality. J Acquir Immune Defic Syndr. 2008;47(4):472-476.

82. van Eijk AM, Ayisi JG, ter Kuile FO, et al. HIV, malaria, and infant anemia as risk factors for postneonatal infant mortality among HIVseropositive women in Kisumu, Kenya. J Infect Dis. 2007;196(1): 30-37.

83. Ezeamama AE, Spiegelman D, Hertzmark E, et al. HIV infection and the incidence of malaria among HIV-exposed children from Tanzania. $J$ Infect Dis. 2012;205(10):1486-1494.

84. Rogers MF, Thomas PA, Starcher ET, Noa MC, Bush TJ, Jaffe HW. Acquired immunodeficiency syndrome in children: report of the Centers for Disease Control National Surveillance, 1982 to 1985. Pediatrics. 1987;79:1008-1014.

85. Pizzo PA, Wilfert CM. Markers and determinants of disease progression in children with HIV infection. J Acquir Immune Defic Syndr Hum Retrovirol. 1995;8(1):30-44.

86. Malamba S, Hladik W, Reingold A, et al. The effect of HIV on morbidity and mortality in children with severe malarial anaemia. Malar J. 2007;6:143.

87. Davenport GC, Ouma C, Hittner JB, et al. Hematological predictors of increased severe anemia in Kenyan children coinfected with Plasmodium falciparum and HIV-1. Am J Hematol. 2010;85(4):227-233.

88. Karp CL, Auwaerter PA. Coinfection with HIV and tropical infectious diseases - II: helminthic, fungal, bacterial, and viral pathogens. Clin Infect Dis. 2007;45(9):1214-1220.

89. Kwenti TE, Moye AL, Wiylanyuy AB, Njunda LA, Nkuo-Akenji T. Variation in the immune responses against Plasmodium falciparum merozoite surface protein-1 and apical membrane antigen-1 in children residing in the different epidemiological strata of malaria in Cameroon. Malar J. 2017;16:453

90. Troye-Blomberg M, Berzins K. Immune interactions in malaria coinfections with other endemic infectious diseases: implications for the development of improved disease interventions. Microbes Infect. 2008;10(9):948-952.

91. Ryan-Payseur B, Ali Z, Huang D, et al. Virus infection stages and distinct Th1 or Th17/Th22 T-cell responses in malaria/SHIV coinfection correlate with different outcomes of disease. J Infect Dis. 2011;204(9):1450-1462.

92. Trott KA, Richardson A, Hudgens MA, Abel K. Immune activation and regulation in simian immunodeficiency virus-Plasmodium fragilecoinfected rhesus macaques. J Virol. 2013;87(17):9523-9537.

93. Jaworowski A, Fernandes LA, Yosaatmadja F, et al. Relationship between human immunodeficiency virus type 1 coinfection, anemia, and levels and function of antibodies to variant surface antigens in pregnancy-associated malaria. Clin Vaccine Immunol. 2009;16(3):312-319.

94. Keen J, Serghides L, Ayi K, et al. HIV impairs opsonic phagocytic clearance of pregnancy-associated malaria parasites. PLoS Med. 2007;4(5):e181.

95. Dembo EG, Mwapasa V, Montgomery J, et al. Impact of human immunodeficiency virus infection in pregnant women on variant-specific immunity to malaria. Clin Vaccine Immunol. 2008;15(4):617-621.

96. Subramaniam KS, Skinner J, Ivan E, et al. HIV malaria co-infection is associated with atypical memory $\mathrm{B}$ cell expansion and a reduced antibody response to a broad array of Plasmodium falciparum antigens in Rwandan adults. PLoS One. 2015;10(4):e0124412.

97. Berg A, Patel S, Gonca M, et al. Cytokine network in adults with falciparum malaria and HIV-1: increased IL-8 and IP-10 levels are associated with disease severity. PLoS One. 2014;9(12):e114480.

98. Anyona SB, Kempaiah P, Davenport GC, et al. Suppressed circulating bicyclo-PGE2 levels and leukocyte COX-2 transcripts in children coinfected with P. falciparum malaria and HIV-1 or bacteremia. Biochem Biophys Res Commun. 2013;436(4):585-590. 
99. World Health Organization. Malaria in HIV/AIDS Patients. Geneva: WHO; 2017.

100. Kredo T, Mauff $\mathrm{K}$, van der Walt JS, et al. Interaction between artemether-lumefantrine and nevirapine-based antiretroviral therapy in HIV-1-infected patients. Antimicrob Agents Chemother. 2011;55(12):5616-5623.

101. Byakika-Kibwika P, Lamorde M, Mayito J, et al. Significant pharmacokinetic interactions between artemether/lumefantrine and efavirenz or nevirapine in HIV-infected Ugandan adults. J Antimicrob Chemother. 2012;67(9):2213-2221.

102. van Geertruyden JP, Mulenga M, Mwananyanda L, et al. HIV-1 immune suppression and antimalarial treatment outcome in Zambian adults with uncomplicated malaria. J Infect Dis. 2006;194(7):917-925.

103. Laufer MK, van Oosterhout JJ, Thesing PC, et al. Malaria treatment efficacy among people living with HIV: the role of host and parasite factors. Am J Trop Med Hyg. 2007;77(4):627-632.

104. Patnaik P, Jere CS, Miller WC, et al. Effects of HIV-1 serostatus, HIV-1 RNA concentration, and CD4 cell count on the incidence of malaria infection in a cohort of adults in rural Malawi. J Infect Dis. 2005;192(6):984-991.

105. Kayentao K, Guirou EA, Nyunt MM, Doumbo OK. Preliminary study of quinine pharmacokinetics in pregnant women with malaria-HIV co-infection. Am J Trop Med Hyg. 2014;90(3):530-534.

106. Timmermans S, Tempelman C, Godfried $\mathrm{MH}$, et al. Nelfinavir and nevirapine side effects during pregnancy. AIDS. 2005;19(8):795-799.

107. Sanne I, Mommeja-Marin H, Hinkle J, et al. Severe hepatotoxicity associated with nevirapine use in HIV-infected subjects. $J$ Infect Dis. 2005;191(6):825-829.

108. Jacobson MA, Besch CL, Child C, et al. Primary prophylaxis with pyrimethamine for toxoplasmic encephalitis in patients with advanced human immunodeficiency virus disease: results of a randomized trial. J Infect Dis. 1994;169(2):384-394.

109. Leport C, Chêne G, Morlat P, et al. Pyrimethamine for primary prophylaxis of toxoplasmic encephalitis in patients with human immunodeficiency virus infection: a double-blind, randomized trial. J Infect Dis. 1996;173(1):91-97.

110. Lek-Uthai U, Suwanarusk R, Ruengweerayut R, et al. Stronger activity of human immunodeficiency virus type 1 protease inhibitors against clinical isolates of Plasmodium vivax than against those of $P$. falciparum. Antimicrob Agents Chemother. 2008;52(7):2435-2441.

111. Hobbs CV, Voza T, Coppi A, et al. HIV protease inhibitors inhibit the development of preerythrocytic-stage plasmodium parasites. J Infect Dis. 2009;199(1):134-141.

112. Savarino A, Lucia MB, Rastrelli E, et al. Anti-HIV effects of chloroquine: inhibition of viral particle glycosylation and synergism with protease inhibitors. J Acquir Immune Defic Syndr. 2004;35(3):223-232.

113. Oguariri RM, Adelsberger JW, Baseler MW, Imamichi T. Evaluation of the effect of pyrimethamine, an anti-malarial drug, on HIV-1 replication. Virus Res. 2010;153(2):269-276.

114. Mohapatra PK, Pachuau E, Kumar C, et al. HIV-malaria interactions in north-east India: a prospective cohort study. Indian J Med Res. 2017;145(3):387-394.

115. Kamya MR, Gasasira AF, Achan J, et al. Effects of trimethoprimsulfamethoxazole and insecticide-treated bednets on malaria among HIV-infected Ugandan children. AIDS. 2007;21(15):2059-2066.

116. Katrak S, Gasasira A, Arinaitwe E, et al. Safety and tolerability of artemether-lumefantrine versus dihydroartemisinin-piperaquine for malaria in young HIV-infected and uninfected children. Malar $J$. 2009;8:272.

117. Kakuru A, Achan J, Muhindo MK, et al. Artemisinin-based combination therapies are efficacious and safe for treatment of uncomplicated malaria in HIV-infected Ugandan children. Clin Infect Dis. 2014;59(3):446-453.

118. Schürmann D, Bergmann F, Albrecht $\mathrm{H}$, et al. Twice-weekly pyrimethamine-sulfadoxine effectively prevents Pneumocystis carinii pneumonia relapse and toxoplasmic encephalitis in patients with AIDS J Infect. 2001;42(1):8-15.
119. Hamer D, Mwanakasale V, Chalwe V, et al. Intermittent presumptive therapy of malaria with SP in HIV-seropositive Zambian women: a placebo-controlled, randomized trial. Poster presented at: 54th Annual Meeting of the American Society of Tropical Medicine and Hygiene; December 11-15, 2005; Washington, DC.

120. Raviglione MC, Dinan WA, Pablos-Mendez A, Palagiano A, Sabatini MT. Fatal toxic epidermal necrolysis during prophylaxis with pyrimethamine and sulfadoxine in a human immunodeficiency virus-infected person. Arch Intern Med. 1988;148(12):2683-2685.

121. World Health Organization. Malaria and HIV/AIDS interactions and implications: conclusions of a technical consultation convened by WHO, 23-25 June 2004. 2004. Available from: http://apps.who. int/iris/bitstream/handle/10665/70076/WHO_HIV_2004.08_eng. pdf? sequence=1\&isAllowed=y. Accessed April 2, 2018.

122. Parise ME, Ayisi JG, Nahlen BL, et al. Efficacy of sulfadoxinepyrimethamine for prevention of placental malaria in an area of Kenya with a high prevalence of malaria and human immunodeficiency virus infection. Am J Trop Med Hyg. 1998;59(5):813-822.

123. ter Kuile FO, van Eijk AM, Filler SJ. Effect of sulfadoxine-pyrimethamine resistance on the efficacy of intermittent preventive therapy for malaria control during pregnancy: a systematic review. JAMA. 2007;297(23):2603-2616.

124. Moore RD, Fortgang I, Keruly J, Chaisson RE. Adverse events from drug therapy for human immunodeficiency virus disease. Am J Med. 1996;101(1):34-40.

125. Colebunders R, Bahwe Y, Nekwei W, et al. Incidence of malaria and efficacy of oral quinine in patients recently infected with human immunodeficiency virus in Kinshasa, Zaire. $J$ Infect. 1990;21(2): $167-173$

126. Greenberg AE, Nsa W, Ryder RW, et al. Plasmodium falciparum malaria and perinatally acquired human immunodeficiency virus type 1 infection in Kinshasa, Zaire: a prospective, longitudinal cohort study of 587 children. $N$ Engl J Med. 1991;325(2):105-109.

127. Gasasira AF, Kamya MR, Achan J, et al. High risk of neutropenia in HIV-infected children following treatment with artesunate plus amodiaquine for uncomplicated malaria in Uganda. Clin Infect Dis. 2008;46(7):985-991.

128. Malamba S, Sandison T, Lule J, et al. Plasmodium falciparum dihydrofolate reductase and dihyropteroate synthase mutations and the use of trimethoprim-sulfamethoxazole prophylaxis among persons infected with human immunodeficiency virus. Am J Trop Med Hyg. 2010;82(5):766-771

129. Thera MA, Sehdev PS, Coulibaly D, et al. Impact of trimethoprimsulfamethoxazole prophylaxis on falciparum malaria infection and disease. J Infect Dis. 2005;192(10):1823-1829.

130. Hamel MJ, Poe A, Bloland P, et al. Dihydrofolate reductase I164L mutations in Plasmodium falciparum isolates: clinical outcome of 14 Kenyan adults infected with parasites harbouring the I164L mutation. Trans R Soc Trop Med Hyg. 2008;102(4):338-345.

131. Quinn TC, Wawer MJ, Sewankambo N, et al. Viral load and immune heterosexual transmission of human immunodeficiency virus type 1 . N Engl J Med. 2000;342(1):921-929.

132. Skinner-Adams TS, Butterworth AS, Porter KA, et al. The frequency of malaria is similar among women receiving either lopinavir/ritonavir or nevirapine-based antiretroviral treatment. PLoS One. 2012;7(4):e34399.

133. Natureeba P, Ades V, Luwedde F, et al. Lopinavir/ritonavir-based antiretroviral treatment (ART) versus efavirenz-based ART for the prevention of malaria among HIV-infected pregnant women. $J$ Infect Dis. 2014;210(12):1938-1945.

134. He Z, Qin L, Chen L, et al. Synergy of human immunodeficiency virus protease inhibitors with chloroquine against Plasmodium falciparum in vitro and Plasmodium chabaudi in vivo. Antimicrob Agents Chemother. 2008;52(7):2653-2656.

135. He Z, Chen L, You J, Qin L, Chen X. Antiretroviral protease inhibitors potentiate chloroquine antimalarial activity in malaria parasites by regulating intracellular glutathione metabolism. Exp Parasitol. 2009;123(2):122-127. 
136. Mishra LC, Bhattacharya A, Sharma M, Bhasin VK. HIV protease inhibitors, indinavir or nelfinavir, augment antimalarial action of artemisinin in vitro. Am J Trop Med Hyg. 2010;82(1):148-150.

137. He Z, Chen L, You J, Qin L, Chen X. In vitro interactions between antiretroviral protease inhibitors and artemisinin endoperoxides against Plasmodium falciparum. Int J Antimicrob Agents. 2010;35(2):191-193.

138. Hobbs CV, Gabriel EE, Kamthunzi P, et al. Malaria in HIV-infected children receiving HIV protease-inhibitor- compared with non-nucleoside reverse transcriptase inhibitor-based antiretroviral therapy: IMPAACT P1068s, substudy to P1060. PLoS One. 2016;11(12):e0165140.

139. Achan J, Kakuru A, Ikilezi G, et al. Antiretroviral agents and prevention of malaria in HIV-infected Ugandan children. $N$ Engl J Med. 2012;367(22):2110-2118.

140. Mermin J, Ekwaru JP, Liechty CA, et al. Effect of co-trimoxazole prophylaxis, antiretroviral therapy, and insecticide-treated bednets on the frequency of malaria in HIV-1-infected adults in Uganda: a prospective cohort study. Lancet. 2006;367(9518):1256-1261.
141. Zigah M. Prevalence and Risk Factors Associated with Malaria and HIV co-Infection among Adult Persons Living with HIV Attending Margret Marquart Catholic Hospital, Kpando [master's thesis]. Accra: University of Ghana; 2016.

142. Verguet S, Kahn JG, Marseille E, Jiwani A, Kern E, Walson JL. Are long-lasting insecticide-treated bednets and water filters cost-effective tools for delaying HIV disease progression in Kenya? Glob Health Action. 2015;8:27695.

143. Rerks-Ngarm S, Pitisuttithum P, Nitayaphan S, et al. Vaccination with ALVAC and AIDSVAX to prevent HIV-1 infection in Thailand. $N E n g l$ J Med. 2009;361(23):2209-2220.

144. Maxmen A. HIV-vaccine strategy sought. Nature. 2018;555:17-18.

145. Frencher JT, Ryan-Pasyeur BK, Huang D, et al. SHIV antigen immunization alters patterns of immune responses to SHIV/malaria coinfection and protects against life-threatening SHIV-related malaria. J Infect Dis. 2013;208(2):260-270.
Research and Reports in Tropical Medicine

\section{Publish your work in this journal}

Research and Reports in Tropical Medicine is an international, peerreviewed, open access journal publishing original research, case reports, editorials, reviews and commentaries on all areas of tropical medicine, including: Diseases and medicine in tropical regions; Entomology; Epidemiology; Health economics issues; Infectious disease; Laboratory
Dovepress

science and new technology in tropical medicine; Parasitology; Public health medicine/health care policy in tropical regions; and Microbiology. The manuscript management system is completely online and includes a very quick and fair peer-review system. Visit http://www.dovepress. com/testimonials.php to read real quotes from published authors.

Submit your manuscript here: https://www.dovepress.com/research-and-reports-in-tropical-medicine-journal 